\title{
DÜBLIN
}

Technological University Dublin

ARROW@TU Dublin

2016-03-22

\section{The welfare effects of nationalization in a mixed duopoly public transport market}

\author{
Feifei Qin \\ Soochow University, merryqff@hotmail.com \\ Xiaoning Zhang \\ Tongji University, cexzhang@tongji.edu.cn \\ Eoin Plant \\ Technological University Dublin, Eoin.Plant@tudublin.ie
}

Follow this and additional works at: https://arrow.tudublin.ie/nitlart

Part of the Business Administration, Management, and Operations Commons, and the Civil and Environmental Engineering Commons

\section{Recommended Citation}

Qin, F., Zhang, X. and Plant, E. (2016) The welfare effects of nationalization in a mixed duopoly public transport market. Operational Research Online 22nd. March 2016.

This Article is brought to you for free and open access by the National Institute for Transport and Logistics at ARROW@TU Dublin. It has been accepted for inclusion in Articles by an authorized administrator of ARROW@TU Dublin. For more information, please contact arrow.admin@tudublin.ie, aisling.coyne@tudublin.ie, gerard.connolly@tudublin.ie.

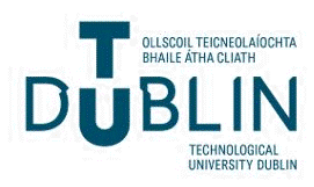




\title{
The welfare effects of nationalization in a mixed duopoly public transport market
}

\author{
Feifei Qin ${ }^{1}$ Xiaoning Zhang $^{2} \cdot$ Eoin Plant $^{3}$
}

Received: 26 March 2015/Revised: 5 March 2016/Accepted: 11 March 2016

(C) Springer-Verlag Berlin Heidelberg 2016

\begin{abstract}
Recently, many cities have launched new rail transit lines. Once these new rail transit lines start commercial operation, they will play important roles as competitors to conventional bus services. In this paper, the effects of nationalization on equilibria have been studied in a mixed duopoly public transport market, in which one publicly-owned rail transit operator competes with one private bus operator. Two numerical case studies show the nationalization of a rail transit company is always socially desirable both in Bertrand pricing game in the short run and in Nash non-cooperative game in the long run.
\end{abstract}

Keywords Mixed duopoly transit market · Nash non-cooperative competition · Degree of nationalization

Xiaoning Zhang

cexzhang@tongji.edu.cn

Feifei Qin

merryqff@hotmail.com

Eoin Plant

eoin.plant@dit.ie

1 School of Urban Rail Transportation, Soochow University, No. 1 Shizi Street, Suzhou 215006, China

2 School of Economics and Management, Tongji University, Siping Road 1239, Shanghai 200092, China

3 School of Transport Engineering, Environment and Planning, National Institute for Transport and Logistics, Dublin Institute of Technology, Bolton Street, Dublin 1, Ireland 


\section{Introduction}

Since the 1990s, in parallel with the trend towards deregulation and privatization, the organizations of public transport in many cities have been undergoing a radical transformation. As for the bus market, it exhibits a transition from a state-owned monopolistic form to a private competition regime in some developing regions and transition countries, such as China. Under franchise agreements, private bus companies can freely provide local services to residents. However, due to the huge capital requirement and substantial economies of scale, most rail transit systems around the world are typically operated by state-owned enterprises (SOEs). Since the 2000s, in order to transform SOEs from cost centers to economic entities responsible for certain profit targets, transit authorities have begun to restructure these SOEs into limited liability companies or joint stock companies, which can be termed as "corporatization" or "partial privatization". Consequently, the prevailing organization in urban public transport market presents such a structure that one (semi-) public rail transit operator competes with one or several private bus companies, which suggests the presence of a mixed oligopoly. ${ }^{1}$ As an example, Shanghai-one of the largest cities in China, has more than 1000 bus lines, served by more than 10 private bus companies. However, all rail transit lines are only operated by one company-Shengtong Metro Company, which was originally a complete public entity. In 2000, it was reformed as a semi-public cooperation with $63.65 \%$ of its share holding by Shanghai municipality. Mixed oligopolies are also common in some developing countries' cities (such as Santiago in Chile, Kuala Lumpur in Malaysia), in which multiple operators with different ownership are vying for passengers. Even in the developed countries, such as Norway, Sweden, the public governments also hold some degree of ownership in transport firms serving local markets (Jørgensen and Santos 2014).

While the coexistence of public and private operators become prevailing in the local transport sector, overall it is still a new competition form. In such a mixed oligopoly, public and private operators have a different management goal, which raises important issues on pricing and service level decisions. On the service level aspect, private operators aim to maximize its profit, so both private monopoly and oligopoly competition intend to provide much less service frequency than the socially desired level. In some Chinese cities, it is frequently reported public transport passengers often suffer from long waiting times due to inadequate service levels afforded by private operators. On the price aspect, private operators may charge high fare which eventually hurts the whole welfare. Inefficient service supplies of private monopoly and oligopoly may overshadow the possible benefits of private ownership, motivating the entry of welfare-maximizing public operators to compete against the profit-maximizing private firms. However, there is still a debate as to whether the mixed oligopoly competition can contribute to adjusting the market failures arising from private oligopoly. Being aware of these issues, the

\footnotetext{
1 In the field of industrial economics, mixed oligopoly refers to the competition between public firms, which are instructed to maximize their contributions to welfare, and profit-maximization private companies.
} 
objective of this paper is to investigate the market outcomes and welfare effects of the mixed oligopoly competition in an urban transport market, which is necessary and timely given that the mixed oligopoly is present in a broad range of countries. More specifically, we consider the strategic interactions between one public rail transit company and one private bus company and attempt to answer the following questions: if one rail transit operator chooses to partially maximize consumer surplus rather than to solely maximize its own profit, how will this affect equilibria and, most importantly, could it really contribute to increasing social welfare as its organizational objective concerns?

The deregulation and privatization in the urban transport market have led to extensive research on the strategic behaviors of oligopolistic competition during recent decades, using either Cournot (e.g., Viton 1981; Oldfield and Emmerson 1986; Williams and Abdulaal 1993) or Bertrand (e.g., Braid 1986; De Palma and Leruth 1989; Wang and Yang 2005; Wichiensin et al. 2007) games. These studies provide considerable insights into private oligopolistic competitions. Moreover, mixed competition between public and private firms is also prevalent in a diverse range of industries, leading to extensive research on the mixed oligopoly (MO) in economic theory (See, De Fraja and Delbono 1990; Cremer et al. 1991; Anderson et al. 1997; Matsumura 1998; Fujiwara 2007). While there is a huge literature on mixed oligopoly in some industrial sectors, such as telecommunications and banking sectors, only a little attention has been paid to modelling mixed oligopolistic competitions in the transport market. For the seaport industry, Czerny et al. (2014) explored the effect of privatization a port for a local market. Matsushima and Takauchi (2014) investigated how port privatization affects port charges, profits and welfare elements from an international perspective. In the aviation sector, Matsumura and Matsushima (2012) and Mantin (2012) investigated behavioural patterns of airports for international air transport markets, where one domestic publicly-owned airport competes against one private airport in another country. In addition to these intra-mode competition models, Yang and Zhang (2012) investigated the effect of inter-modal competition between air transport and high speed rail (HSR) in a mixed duopoly framework. Very recently, D'Alfonso et al. (2014) analyzed the impacts of competition between one private airline and one public HSR on the environment and social welfare. In the urban transport market, Cantos-Sánchez and Moner-Colonques (2006) explored frequency and pricing competition between one private bus and one public rail transit using a quadratic address model. Employing a quadratic utility function, Clark et al. (2009) compared equilibrium results that arise from collusion, applying Cournot and Bertrand competitions for a mixed duopoly bus market.

The review of the above-mentioned papers reveals three common features. First, the above studies only focus on full nationalization. In reality, however, the transport market is likely to have partially nationalized transport operators, especially in the urban transport market. For example, in China, Hangzhou government holds $51 \%$ of the share in Hangzhou Metro Company; the Norwegian Transit Authority holds the majority of shares in 36 bus companies. Despite these prevailing real world cases, the implications of partial privatization for frequency and pricing choices have not been investigated in the transport sector. Our research 
intends to fill in this gap. Second, all these papers adopt linear demand functions, which can easily obtain analytical solutions. But, when exploring competitions among firms, an attraction model with nonlinear form is superior to linear one since it can not only represent reality more closely but also can reflect the nonlinear effects arising in competitive phenomena (Huang et al. 2013). To this end, we adopt a non-linear demand function (that is, a Logit model) in this paper to obtain more general and practical conclusions. Finally, some studies assumed the aggregate demand for the whole market is inelastic with respect to fare or full cost. Actually, this is a very strict assumption. In this paper, a more realistic case will be developed in which total local transport demand is elastic with respect to the combination of fare and frequency.

The contributions of this paper can be summarized as follows: (1) given the growing importance of partial nationalization in the transport sector, this paper fills the research gap by analyzing the effects of partially nationalizing a rail transit company that competes with a private bus service. (2) in contrast to most mixed oligopoly studies with linear demand function, we employed an attraction demand function with non-linear form to provide more practical and general insights; (3) Using a Chinese case study, two time horizons are analyzed for this vertically and horizontally differentiated mixed duopoly competition: a short time horizon in which operators compete only in fares, and a long time horizon in which they compete in frequency along with the price.

The rest of paper is organized as follows. Section 2 provides a model using a Nash non-cooperative game in a mixed duopoly public transport market. In Sect. 3, to evaluate the effects of nationalization on equilibrium results, two numerical cases for short-run and long-run competitions are conducted by using Suzhou traffic data. Additionally, sensitivity analysis has been carried out to generalize the results. Main findings and recommendations for further research are reported in Sect. 4.

\section{Modeling framework}

\subsection{Basic setting of Nash non-cooperative game}

This study focuses on a mixed duopoly public transport market, in which one semipublic rail transit operator, which is fully or partially concerned with users' benefits, competes with a private bus company, which only considers its own profits. Since each player is trying to "optimize its objective function without prior knowledge of other players' functions" (Evans 1992), these two players make their decisions simultaneously without any collusion and receive payoffs depending on the service levels they offer. In this setting, the Nash non-cooperative Game in the context of mixed duopoly has the following features:

Players Nowadays, although multiple private bus companies prevail in some cities, few overlapping operating situations lead us to view them as one virtual operator. Thus, we theoretically assume only one bus operator competes with one (semi-) public rail transit operator on an isolated route during a given period. 
Strategies In the field of transport modelling, the strategic interaction occurs either in the price dimension (Bertrand) or in the quantity dimension (Cournot). What type of competition is appropriate not only depends on the strategic variables employed but also largely depends on the production technology and the time horizon (Kreps and Scheinkman 1983). Cournot competition may be applicable when the capacity is difficult to adjust (e.g., rail, airport) and productions are perceived as perfect substitutes. But, when capacities are flexible (e.g., bus) and products are more differentiated, a Bertrand competition would be more appropriate (Quinet and Vickerman 2004). In the case of a competition between bus and rail transit, it is not evident which type of competition is more proper based on the ease or difficulty of capacity adjustment. Bus and rail services are not only horizontally differentiated in terms of their distinct mode features but also vertically differentiated in terms of different service qualities. This implies that the substitution between these two modes is imperfect and the products are differentiated. As a result, we believe a differentiated Bertrand competition may be reasonable for the short run competition.

Besides price and quantity, frequency is another important strategic device. In the short run, since the increasing number of departures could require additional fleets, frequency is difficult to change. Thus, operators only compete over price, assuming frequency is exogenously given. But, in the long run, operators may compete over frequency along with fare since operators can relocate stops and buying more fleet.

Payoff In the field of mixed oligopoly, the conventional objective function of one public company is to maximize social welfare, which is the sum of consumer surplus, its own profit and the profits of private companies. However, in the context of competition, it is somewhat unreasonable to assume the rail transit company competing against one bus company also needs to consider its rival's profit. Therefore, we assume, in addition to the rail company's profit, the rail company takes consumers' interests into account when it decides fare and frequency. The profit of the bus company is out of its consideration. This kind of treatment is adopted by much recent literature (Clark et al. 2009; Jørgensen and Santos 2014). It is reasonable to assume one private bus company is only concerned with maximizing its profit.

\subsection{Demand functions and operating cost}

In view of the mixed duopoly competition between one public rail transit operator and one private bus operator, this sub-section begins by constructing a demand function for operator $i$ (Hereafter, the subscript $r$ will be used to denote rail transit and the subscript $b$ for bus), which conventionally takes the following form:

$$
Q_{i}=Q^{*}\{\xi, c c\} M_{i} \quad i=b, r
$$

where, $\mathrm{Q}_{i}$ is the number of passengers selecting public transport service $i$. $\mathrm{Q}^{*}\{\xi, c c\}$ represents total traffic demand of public transport sector, which is the function of composite costs $(c c)$ and one positive parameter $\xi(\xi>0) . \mathrm{M}_{i}$ denotes the market share of public transport service afforded by operator $i$. 
The total demand for local public transport is assumed to be an exponential function of composite costs $(c c)^{2}$ :

$$
Q^{*}=\bar{Q}^{*} \exp [-\xi(c c-\overline{c c})]
$$

The composite cost $(c c)$ represents the expected disutility of using public transport modes. A bar over a variable denotes its value in a reference case before competition takes place. Thus, $\bar{Q}^{*}$ is the initial total public transport demand in a benchmark situation and $\overline{c c}$ means the composite cost of a reference case. Total demand for local public transport is elastic, because any changes in composite cost will shift the travelling demand between public transport modes and private transport modes (such as private cars, motorbikes, etc.).

To reflect the elasticity of total demand change with respect to travellers' composite costs, we further specify the formulation of composite costs as:

$$
c c=-\frac{1}{\theta} \ln \sum \exp \left(-\theta C_{i}\right)
$$

$\mathrm{C}_{i}$ denotes the generalized cost of travelling by public transport mode $i$. $\theta$ is a positive dispersion parameter. In this paper, individual travellers' mode choices are assumed to be based on minimizing their generalized cost per trip $\left(\mathrm{C}_{i}\right)$, which equals the sum of the monetary cost (fare) and the travel time weighted by value of time.

$$
C_{i}=P_{i}+\alpha_{1} \rho T_{i}+\alpha_{2} \rho\left(1 / 2 f_{i}\right)
$$

where $\mathrm{P}_{i}$ is the fare charged by public transport operator $i . \mathrm{T}_{i}$ is the average invehicle travelling time using public transport service $i$, which can be computed based on travelling distance and speed. Normally, during rush hour, the public transport services are much more frequent. Thus, the average waiting time can be roughly estimated from one-half the inverse of frequency $\left(f_{i}\right) . \rho$ is the value of time (VOT). $\alpha_{1}$ and $\alpha_{2}$ are parameters that measure different weights that passengers put on in-vehicle travelling time and waiting time. To focus on the principal aspects, this paper confines itself to the case of one homogeneous passenger group, which indicates all passengers are identical in regard to the value of time. Furthermore, for both bus and rail transit services, since the station location and number of stops have been decided in the planning stage, accessing time costs have not been included in the generalized cost function.

Turning to the specifications of travelling mode choices, the market share of operator $i$ is given by the Binary Logit form:

$$
M_{i}=\frac{\exp \left(-\theta C_{i}\right)}{\sum_{i} \exp \left(-\theta C_{i}\right)}
$$

Inserting Eqs. (5), (2) and (3) into Eq. (1), after some manipulation, the number of passengers that choose public transport service $i$ is:

\footnotetext{
${ }^{2}$ With this exponential function, the elasticity of total public transport demand will be proportional to composite cost $\left(\varepsilon_{c c}=\left(\partial Q^{*} / \partial c c\right)\left(c c / Q^{*}\right)=(-\xi) c c\right)$. This is a property of public transport demand which has been found in many studies (see Johansen et al. 2001; Fearnley et al. 2004).
} 


$$
Q_{i}=\bar{Q}^{*}\left[\sum_{i} \exp \left(-\theta \bar{C}_{i}\right)\right]^{-\frac{\xi}{\theta}} \exp \left(-\theta C_{i}\right)\left[\sum_{i} \exp \left(-\theta C_{i}\right)\right]^{\frac{\xi}{\theta}-1}
$$

where $\bar{C}_{i}$ denotes the generalized cost of mode $i$ in reference case. To show the impact of price and frequency on travel demand, we evaluate partial derivatives of Eq. (6) after substituting into (4) from (4) and (5):

$$
\begin{gathered}
\frac{\partial Q_{i}}{\partial P_{i}}=-Q_{i}\left(\xi M_{i}+\theta M_{j}\right)<0 \quad i, j \in\{b, r\} \quad i \neq j \\
\frac{\partial Q_{i}}{\partial P_{j}}=(\theta-\xi) Q_{i} M_{j}>0 \quad i \neq j \\
\frac{\partial Q_{i}}{\partial f_{i}}=\frac{\alpha_{2} \rho}{2 f_{i}^{2}} Q_{i}\left(\xi M_{i}+\theta M_{j}\right)>0 \\
\frac{\partial Q_{i}}{\partial f_{j}}=(\xi-\theta) \frac{\alpha_{2} \rho}{2 f_{j}^{2}} Q_{i} M_{j}<0
\end{gathered}
$$

Various studies have shown that $(\theta-\xi)>0$ in the urban public transport market (Williams and Abdulaal 1993). From the above equations, it is clear that a high fare of one public transport service will reduce its own demand and increase the demand of its competitor. An increase of frequency will boost its own demand rate and simultaneously reduce the demand of its competitor.

The variable operating costs of public transport service $i\left(\mathrm{OC}_{i}\right)$ is the sum of marginal passenger cost $\left(\mathrm{c}_{i 0}\right)$ plus the variable cost $\left(\mathrm{c}_{i 1}\right)$ associated with service frequencies:

$$
O C_{i}=c_{i 0} Q_{i}+c_{i 1} f_{i}
$$

\subsection{Price competition in the short run}

In a mixed oligopoly market, the bus operator is viewed as a pure commercially oriented company, which is only concerned with maximizing its profit. The profit of private bus company $\left(\pi_{b}\right)$ is defined as the fare-box revenue minus the costs associated with bus operation $\left(O C_{b}\right)$ :

$$
O F_{b}=\pi_{b}=P_{b} Q_{b}-O C_{b}
$$

As mentioned earlier, the public rail transit operator maximizes a weighted combination of its profit and consumer surplus of the whole public transport market. Given the proposed exponential demand function, the explicit form of consumer surplus can be simply expressed as:

$$
C S=Q^{*} / \xi
$$


This simple expression for consumer surplus was derived by Evans (1992), and has since been used extensively by many studies (Williams and Abdulaal 1993; Wichiensin et al. 2007). The parameter $\xi$ can be interpreted from two perspectives. Firstly, $\xi$ quantifies the sensitivity of the total local transport demand with respect to composite costs. The second interpretation is that the inverse of $\xi$ is the average perceived benefit experienced by one representative traveler. Accordingly, the rail operator's objective function can be specified as:

$$
O F_{r}=\sigma C S+\pi_{r}=\sigma\left(Q^{*} / \xi\right)+\left(P_{r} Q_{r}-O C_{r}\right)
$$

The continuous parameter $\sigma$, which ranges from 0 to 1 , can be referred as the "weight" attached to consumer surplus. It gives a measurement of nationalization degree. $\sigma=0$ signifies the rail company is solely concerned with its profits. As $\sigma$ rises, the weight on consumer surplus becomes heavier in rail transit firm's objective function. When $\sigma=1$, the rail transit operator is fully nationalized and aims to maximize the sum of consumer surplus and its own profit.

In this mixed duopoly market, each operator attempt to maximize its distinct objective function with respect to strategic valuables, subject to a capacity constraint.

$$
\begin{array}{ll}
\underset{P_{i}, f_{i}}{\operatorname{Max}} & O F_{i} \\
\text { s.t. } & Q_{i} \leq K_{i} f_{i}
\end{array}
$$

$\mathrm{K}_{i}$ is the designed vehicle capacity of public transport services $i$.

In the short run, since the expansion of rolling stocks is strongly limited, the service frequency is assumed to be exogenously given. To this end, competition between two public transport modes is in price only.

By setting the partial derivatives of payoff functions with respect to fare equal to zero, and performing some manipulation, Nash equilibrium prices $\left(\mathrm{P}_{i}^{N E ;}\right.$ the superscript $N E$ denotes equilibrium) for operator $i$ can be calculated. Details of the derivation can be referred to "Appendix 1":

$$
P_{i}^{N E}=\frac{(1-\sigma) \delta}{\theta M_{j}+\xi M_{i}}+c_{i 0}
$$

The indicator variable $\delta$ takes on the value of one for rail transit and 0 for bus.

Next, we further partially differentiate Eq. (16) with respect to its rival's price $\left(P_{j}\right)$

$$
\frac{\partial^{2} O F_{i}}{\partial P_{i} \partial P_{j}}=\frac{\partial P_{i}^{N E}}{\partial P_{j}}=M_{j}\left(1-M_{j}\right)(\theta-\xi)
$$

A closer look at the above mathematical expressions (16) for equilibrium fares gives rise to some interesting insights. First, in the absence of capacity constraints, the equilibrium price is equal to marginal passenger cost of public transport service $i\left(c_{i 0}\right)$ plus a mark-up, which relates to the market share of public transport services. Second, when $\sigma=1$ (that is, the public rail transit company considers whole 
consumer surplus), the rail company consequently sets its fare equal to marginal $\operatorname{cost}\left(c_{i 0}\right)$. Finally, since we have assumed that $(\theta-\xi)>0$ in urban public transport market, we have $\partial^{2} O F / \partial P_{i} \partial P_{j}>0$, which implies one operator's marginal profit increases as its competitor's fare increase. That is, the price set by the bus company decrease (increase) in response to the price reduction (increase) of the rail transit company $\left(\partial P_{i}^{N E} / \partial P_{j}>0\right)$. This property matches the well-known definition of the strategic complement in oligopolies.

To test the effect of partial nationalization $(\sigma)$ on equilibrium fares, we invoke the techniques of monotone comparative statics for the following analytical derivations and obtain:

$$
\frac{d P_{r}^{N E}(\sigma)}{d \sigma}=-\frac{\partial^{2} O F_{r} / \partial P_{r} \partial \sigma}{\partial^{2} O F_{r} / \partial P_{r}^{2}}<0
$$

From Eq. (18), it is clear that with an increase of $\sigma$, the equilibrium price falls for rail transit. The explanation could be, an increase in $\sigma$ provides more incentives to rail transit company to reduce its fare for improving consumer surplus. Furthermore, since the equilibrium fares between bus and rail transit are strategic complements, the bus fare correspondingly falls to compete for passengers. So we can conclude in the mixed duopoly market, as the publicly-owned rail transit operator pays more attention to consumer surplus relative to its own profit, equilibrium fares of bus and rail transit both decreases.

\subsection{Frequency-price competition in the long run}

In the long run, since the frequency can be easily adjusted, it is reasonably assumed that public transport operators compete in both price and frequency. To derive the reaction functions for service frequency, a similar procedure is made by partially differentiating the payoff function of operator $i$ with respect to its frequency. After some algebraic manipulation, the equilibrium service frequency is given as (Details of the derivation can be referred to "Appendix 2"):

$$
f_{i}^{N E}=\sqrt{\frac{\alpha_{2} \rho}{2 c_{i 1}} Q_{i}}
$$

Obviously, the Nash Equilibrium frequency follows a "square root formula". By analogy, the mathematical expression of equilibrium frequency can be further differentiated with respect to the frequency of its competitor:

$$
\frac{\partial f_{i}^{N E}}{\partial f_{j}}=\sqrt{\frac{\alpha_{2} \rho}{2 c_{i 1}}} \frac{1}{2} Q_{i}^{-\frac{1}{2}} \frac{\partial Q_{i}}{\partial f_{j}}
$$

From Eq. (10), we have $\partial Q_{i} / \partial f_{j}<0$. Hence, the above equation takes a negative sign, which indicates a marginal increase (decrease) in the frequency of rail transit causes the bus operator to decrease (increase) its service frequency. This concept of 
strategic substitution clearly addresses the relationship of equilibrium frequencies between bus and rail transit in this mixed oligopoly model. ${ }^{3}$

Summarizing the above analysis, we obtain Proposition 1:

Proposition 1 In the mixed duopoly market involving one private bus operator and one public rail transit company, Nash Equilibrium fares are strategic complements. Nash Equilibrium frequencies are strategic substitutes.

Proposition 1 offers an important extension, that is, the conventional concept of strategic substitutes and complements in the private oligopoly can also appropriately fit to the context of a mixed oligopoly model. It can contribute to explaining the strategic behaviors (such as fare and frequency competitions) between the welfaremaximizing public and profit-maximizing private operators.

Next, we investigate the impact of nationalization degree on equilibrium frequency. Given the mathematical specification of equilibrium frequency for rail transit in Eq. (20), we partially differentiate it with respect to $\sigma$ :

$$
\frac{\partial f_{r}^{N E}}{\partial \sigma}=\sqrt{\frac{\alpha_{2} \rho}{2 c_{i 1}}} \frac{1}{2}\left(Q_{r}^{N E}\right)^{-\frac{1}{2}} \frac{\partial Q_{r}^{N E}}{\partial P_{r}^{N E}} \frac{\partial P_{r}^{N E}}{\partial \sigma}
$$

From Eqs. (7) and (21), we have $\partial Q_{r}^{N E} / \partial P_{r}^{N E}<0$ and $\partial P_{r}^{N E} / \partial \sigma<0$, thus we can confirm $\partial f_{r}^{N E} / \partial \sigma>0$. This means the equilibrium frequency of rail transit increases when rail operator places more weight on consumer surplus. Since the equilibrium frequencies between bus and rail are strategic substitutes, an increase in $\sigma$ will decrease the equilibrium frequency for bus $\left(f_{b}^{N E}\right)$.

Proposition 2 summarizes the impact of nationalization degree $(\sigma)$ on equilibrium fares and service frequencies.

Proposition 2 In line with the initial objective of increasing consumer surplus, a lower degree of nationalization leads to (1) lower equilibrium fares for both rail transit and bus; (2) higher equilibrium frequency for rail transit and lower equilibrium frequency of bus.

As noted in Proposition 2, as the rail transit operator concerns consumer surplus more, its fare decreases. Since prices are strategic complements, lower rail transit fare will put downward pressure on bus fare. As a result, bus fare will, in equilibrium, fall as well. On the other hand, the best respond functions of frequencies are downward sloping, indicating frequencies are strategic substitutes. More concerns about consumer surplus leads to an increase in rail transit's equilibrium frequency and this occurs at the expense of a reduction of bus frequency.

\footnotetext{
3 As pointed out by an anonymous referee, the equilibrium result of Cournot competition is equivalent to the outcome of a two-stage game, where there is a simultaneous capacity choice after which price competition occurs (Kreps and Scheinkman 1983). In the mixed monopoly, this equivalence found by Kreps and Scheinkman (1983) is still valid, if assumptions of L-shaped marginal cost function and efficient rationing rule hold (a technical proof is available upon request from the authors). However, if two assumptions are violated, the $\mathrm{K}-\mathrm{S}$ result might not remain valid. Extending the analysis to compare the equilibrium results of Cournot competition with outcomes of two-stage game would be a useful future study, if the demand function can be explicitly converted to inverse demand function.
} 
Next, we analyze how the change of nationalization degree affects passenger demand, consumer surplus and producer surplus. All results are summarized in the following propositions.

Proposition 3 An increase in the level of nationalization (1) increases the total demand of local public transport in the equilibrium $\left(\partial Q^{N E^{*}} / \partial \sigma>0\right) ;(2)$ increases the ridership of rail transit under the equilibrium, but reduces the ridership for bus, $\partial Q_{r}^{N E} / \partial \sigma>0$ and $\partial Q_{b}^{N E} / \partial \sigma<0$.

Proof See "Appendix 3".

The insights behind Proposition 3 are as follows: when the rail operator attaches a high weight to consumer surplus, this welfare concern puts a downward pressure on rail fare and an upward incentive on raising rail frequency. The combination of lower fare and higher frequency makes rail transit services more attractive than before. Thus, its ridership is boosted along with its strengthened market share. However, only concerning its profit, the bus service becomes progressively less attractive, although it also reduces its fares to compete against rail transit.

Proposition 4 Since travellers pay less in the move from a standard duopoly (SD) to a mixed duopoly (MD), the consumer surplus necessarily rises alongside the boost in total public transport demand. At the same time, there is a reduction in producer surplus when we move away from a standard private duopoly (SD) to a mixed duopoly (MD).

Proof See the "Appendix 4".

Whilst the effects of nationalization on consumer surplus and producer surplus are straightforward now, we are not certain whether the increase in consumer surplus can compensate for the loss of producer surplus as the rail transit operator puts more weight on consumer surplus. Therefore, the impact of nationalization on social welfare is still ambiguous. So we turn to a numerical study based primarily on a mixed public transport market in a Chinese city.

\subsection{An extension to a large-scale transit network}

The above analytical modelling provides some useful and interesting insights into the mixed oligopolistic competition. Nonetheless, the above analysis involves only single-path model. In reality, most cities commonly characterized with a large-scale transport network with multiple paths and OD pairs. Thus, it is meaningful to explore the strategic interactions and market equilibrium in a complex transit network of a city.

Considering an urban area, there already exists one public transport network $\mathrm{G}=(\mathrm{N}, \mathrm{A})$ where, $\mathrm{N}$ is set of transit stations (nodes) and $\mathrm{A}$ is the set of transit links with the link $a(a \in \mathrm{A})$. Within a $\mathrm{W}$ set of OD pair, bus and rail transit companies operate parallel services between a particular OD pair, $w(w \in \mathrm{W})$. The notation used for this complex network is given as follows: 
$R_{w} \quad$ Set of transit routes $r$ between OD pair $w$

$v_{a} \quad$ Total passenger flow on transit link $a$;

$h_{r w} \quad$ Passenger flow on path $r, r \in \mathrm{R}_{w}$;

$M_{a}^{i} \quad$ Probability of passengers on link $a$ choosing public transport mode $i$;

$f_{a}^{i} \quad$ Service frequency of public transport mode $i$ on link $a$;

$P_{a}^{i} \quad$ The fare of public transport mode $i$ on link $a$;

$q_{w} \quad$ Passenger flow between OD pair $w$;

$\mathrm{D}_{\mathrm{w}}^{-1} \quad$ Inverse demand function between OD pair $w$;

$\mathrm{cc}_{\mathrm{w}}^{r} \quad$ Composite cost on route $r$ between OD pair $w$;

$\mathrm{OC}_{a}^{i} \quad$ Operating cost of running transit services though link $a$ for operator $i$;

With the above notion, the issue of interest is a mixed oligopolistic equilibrium subject to a stochastic traffic assignment. The problem can be converted as bi-level transit equilibrium model, which involve equilibrium at both lower (Stochastic User Equilibrium, SUE) and upper levels (Nash Equilibrium in the mixed oligopoly market).

\subsubsection{The upper level-mixed oligopolistic equilibrium}

$$
\begin{aligned}
\operatorname{Max}_{O} O F_{b} & =\sum_{w \in W} \sum_{a \in A}\left(P_{a}^{b} v_{a} M_{a}^{b}-O C_{a}^{b}\right) \\
{\operatorname{Max} O F_{r}}_{r} & =\sum_{w \in W} \sum_{a \in A}\left[\sigma\left(v_{a} / \xi\right)-\left(P_{a}^{r} v_{a} M_{a}^{r}-O C_{a}^{r}\right)\right]
\end{aligned}
$$

For each operator $i$, a level of frequency $\left(f_{a}^{i}\right)$ and price charged $\left(P_{a}^{i}\right)$ are the only two variables chosen by each firm subject to the resulting passenger flow being in a stochastic user equilibrium (SUE). The link flow $\left(v_{a}\right)$ can be determined by the following lower problem.

\subsubsection{The lower level-Stochastic user equilibrium}

For a given fare and service frequency, passenger will set their transit routes with the SUE manner. As proved by Lam and Zhou (1999), Lam et al. (2002), the SUE assignment problem is equivalent to the following minimization problem:

$$
\begin{aligned}
\operatorname{Min} & \frac{1}{\theta} \sum_{w \in W} \sum_{r \in R_{w}} h_{r w}\left(\ln h_{r w}-1\right)-\frac{1}{\theta} \sum_{w \in W} q_{w}\left(\ln q_{w}-1\right) \\
& +\sum_{a \in A} c c_{a} v_{a}-\sum_{w \in W} \int_{0}^{q_{w}} D_{w}^{-1}(y) d y
\end{aligned}
$$

Subject to

$$
\begin{aligned}
& v_{a}=\sum_{w \in W} \sum_{r \in R_{w}} \tau_{a r} h_{r w} \quad \tau_{a r}=1 \quad \text { if link } a \text { lies on path } r, 0 \text { otherwise } \\
& q_{w}=\sum_{r \in R_{w}} \delta_{a r} h_{r w} \quad \delta_{w r}=1 \quad \text { if path } r \text { connects OD pair } w, 0 \text { otherwise }
\end{aligned}
$$


The presented bi-level transit network equilibrium problem follows similar modeling principles so that the results do not qualitatively change with respect to the sign-path analytical model presented in the previous section. Nevertheless, with more paths, more links and more OD pairs, competition intensity increases, thus eventually lower the benefits of having a public transport operator.

The bi-level network equilibrium model can be solved by a heuristic algorithm. Since the problem becomes quite complex in a large-scale network, up to now we cannot give an efficient algorithm to solve this bi-level network equilibrium model. In the future, it is much imperative to develop efficient solution algorithms applicable to general network. Moreover, due to the lack of data for a large-scale transport network, the numerical evaluation of the proposed bi-level transit equilibrium model for a real transportation network is also on open issue for the future research.

\section{Numerical case studies}

To shed light on the impacts of partial nationalization on equilibrium outputs under a mixed duopoly market, this section begins with introducing Bertrand pricing game in Case 1, in which service frequency is less flexible in the short run. In Case 2, adding frequency as another strategic device, we illustrate the long-run impact of nationalization on Nash equilibrium solutions. To establish orders of magnitude for key strategic variables and associated welfare elements, Suzhou traffic data are used to gauge the results. Table 1 summarizes all traffic data and parameters used.

In the following numerical calculations, the traffic data and parameters, such as average fares, general operating characteristics of public transport, and value of time

Table 1 Traffic data and parameters

\begin{tabular}{llll}
\hline Description & Measurement & Rail transit & Bus \\
\hline Average running speed $\left(\mathrm{V}_{i}\right)$ & Km/hour & 40 & 20 \\
In-vehicle travelling time $\left(\mathrm{T}_{i}\right)$ & Hour & 0.225 & 0.45 \\
Vehicle capacity $\left(\mathrm{K}_{m i}\right)$ & Passenger/vehicle & 960 & 102 \\
Variable running costs $\left(\mathrm{c}_{i l}\right)$ & $\mathrm{CNY} /$ vehicle-km & 22 & 8.9 \\
Marginal passenger cost $\left(\mathrm{c}_{i o}\right)$ & $\mathrm{CNY} /$ passenger & 0.002 & 0.0015 \\
Fare $\left(\mathrm{P}_{i 0}\right)$ & $\mathrm{CNY}$ & 3 & 1.5 \\
Frequency $\left(f_{i}\right)$ & Vehicle/hour & 12 & 8 \\
Market share $\left(\mathrm{M}_{i 0}\right)$ & Percent $(\%)$ & $84.46 \%$ & $15.54 \%$ \\
Patronage of service $i\left(\mathrm{Q}_{i 0}\right)$ & Passengers/hour & 4223 & 777 \\
Total public transport demand $\left(\bar{Q}^{*}\right)$ & Passengers/hour & 5000 & \\
Value of time $(\rho)$ & $\mathrm{CNY/hour}$ & 10.1 & \\
Scale parameter $(\theta)$ & & 1 & \\
Weights of in-vehicle time $\left(\alpha_{1}\right)$ & & 1 & \\
Weights of waiting time $\left(\alpha_{2}\right)$ & & 2 & \\
Parameter in total transit demand $(\xi)$ & & 0.2 & \\
\hline
\end{tabular}


(VOT), were sourced from the Annual Report of Suzhou Urban Transportation (2008). Furthermore, concerning operating costs of bus, the information stems from Suzhou Bus Group Annual Report (2008). This report illustrates the variable operating costs of running an extra bus kilometre are 8.9 CNY and the marginal cost per passenger journey $0.0015 \mathrm{CNY}$. In terms of rail transit, the figures of variable operating costs (22 CNY per kilometre and $0.002 \mathrm{CNY}$ per passenger) are estimated by referring to the accounting report of Suzhou Metro Company. Hong and Zuo (2006) estimated the sensitivity of transit passengers to changes of traveling costs in several Chinese cities. The results indicate that for a $1 \%$ reduction in traveling costs, there is a $0.1-0.4 \%$ increase in public transport patronage. In order to make the following cases more illustrative, operational features of bus and rail transit, such as their average running speed, vehicle capacity, are also listed in Table 1. Setting the current situation as a reference case, we can compare how fares, frequencies, market shares, social welfare and its constituent parts change with the degree of nationalization. With 5000 commuters per morning peak hour, the rail transit line catches a significantly larger market share $(84.46 \%)$ than the bus $(15.54 \%)$.

\subsection{Case one: the effect of nationalization $(\sigma)$ on equilibra in the short run}

In the short run, public transport operators cannot afford more frequent services due to the additional cost of increasing their fleet. Thus, both operators compete purely on price, assuming service frequencies are exogenously given. In Case one, to assess the impact of the level of nationalization $(\sigma)$ on equilibrium configurations, the analysis begins with the move from standard private duopoly ( $\mathrm{SD}, \sigma=0)$ to a mixed duopoly (MD, $\sigma>0$ ) case. As mentioned earlier, the parameter- $\sigma$, is

Table 2 Effect of nationalization $(\sigma)$ on equilibrium solutions in the short run

\begin{tabular}{lllllll}
\hline & $\sigma=0$ & $\sigma=0.2$ & $\sigma=0.4$ & $\sigma=0.6$ & $\sigma=0.8$ & $\sigma=1$ \\
\hline Bus fare $\left(\mathrm{P}_{b}\right)$ & 1.219 & 1.17 & 1.124 & 1.081 & 1.046 & 1.021 \\
Rail transit fare $\left(\mathrm{P}_{r}\right)$ & 2.643 & 2.326 & 1.945 & 1.463 & 0.828 & 0.002 \\
Market share of bus $\left(\mathrm{M}_{b}\right)$ & $21.98 \%$ & $17.73 \%$ & $13.36 \%$ & $9.04 \%$ & $5.17 \%$ & $2.39 \%$ \\
Market share of rail transit $\left(\mathrm{M}_{r}\right)$ & $78.02 \%$ & $82.27 \%$ & $86.64 \%$ & $90.96 \%$ & $94.83 \%$ & $97.61 \%$ \\
Total public transport demand $\left(\mathrm{Q}^{*}\right)$ & 5458 & 5754 & 6145 & 6701 & 7546 & 8850 \\
Passenger demand of bus $\left(\mathrm{Q}_{b}\right)$ & 1200 & 1020 & 821 & 606 & 390 & 211 \\
Passenger demand of rail transit $\left(\mathrm{Q}_{r}\right)$ & 4258 & 4734 & 5324 & 6095 & 7156 & 8639 \\
Producer surplus $(\mathrm{PS})$ & 10053 & 9499 & 8573 & 6869 & 3623 & -2477 \\
$\quad \Delta$ Profit of bus $\left(\pi_{b}\right)$ & 1184 & 875 & 605 & 338 & 91 & -101 \\
$\quad \Delta$ Profit of rail transit $\left(\pi_{r}\right)$ & 8869 & 8624 & 7968 & 6531 & 3532 & -2376 \\
Consumer surplus $(\mathrm{CS})$ & 27,289 & 28,768 & 30,726 & 33,505 & 37,732 & 44,250 \\
Social welfare $(\mathrm{SW})$ & 37,742 & 38,267 & 39,299 & 40,374 & 41,355 & 41,773 \\
\hline
\end{tabular}

PS is the producer surplus, which is the sum of bus's profit $\left(\pi_{b}\right)$ and rail's profit $\left(\pi_{r}\right)$

$\mathrm{SW}$ is the social welfare, which is the sum of producer surplus (PS) and consumer surplus (CS) 
Table 3 Effect of nationalization $(\sigma)$ on equilibrium solutions in the long run

\begin{tabular}{lllllll}
\hline & $\sigma=0$ & $\sigma=0.1$ & $\sigma=0.3$ & $\sigma=0.5$ & $\sigma=0.7$ & $\sigma=0.9$ \\
\hline Bus fare $\left(\mathrm{P}_{b}\right)$ & 1.253 & 1.221 & 1.158 & 1.097 & 1.038 & 0.889 \\
Rail transit fare $\left(\mathrm{P}_{r}\right)$ & 2.498 & 2.373 & 2.091 & 1.742 & 1.279 & 0.611 \\
Bus frequency $\left(f_{b}\right)$ & 13.62 & 13.02 & 11.58 & 9.61 & 6.35 & 3.53 \\
Rail transit frequency $\left(f_{r}\right)$ & 14.96 & 15.39 & 16.33 & 17.46 & 18.9 & 19.43 \\
Market share of bus $\left(\mathrm{M}_{b}\right)$ & $25.13 \%$ & $22.50 \%$ & $16.93 \%$ & $10.94 \%$ & $4.37 \%$ & $0.75 \%$ \\
Market share of rail transit $\left(\mathrm{M}_{r}\right)$ & $74.87 \%$ & $77.50 \%$ & $83.07 \%$ & $89.06 \%$ & $95.63 \%$ & $99.25 \%$ \\
Total public transport demand $\left(\mathrm{Q}^{*}\right)$ & 5857 & 5987 & 6395 & 6709 & 7320 & 8327 \\
Passenger demand of bus $\left(\mathrm{Q}_{b}\right)$ & 1472 & 1347 & 1066 & 734 & 320 & 62 \\
Passenger demand of rail transit $\left(\mathrm{Q}_{r}\right)$ & 4385 & 4640 & 5229 & 5875 & 7000 & 8265 \\
Producer surplus (PS) & 8735 & 8553 & 7993 & 6976 & 5022 & 965 \\
$\Delta$ Profit of bus $\left(\pi_{b}\right)$ & 753 & 600 & 306 & 35 & -176 & -227 \\
$\Delta$ Profit of rail transit $\left(\pi_{r}\right)$ & 7982 & 7953 & 7687 & 6941 & 5198 & 1192 \\
Consumer surplus $(\mathrm{CS})$ & 29,287 & 29,933 & 31,472 & 33,542 & 36,599 & 41,637 \\
Social welfare $(\mathrm{SW})$ & 38,022 & 38,489 & 39,465 & 40,518 & 4162 & 42602 \\
\hline
\end{tabular}

continuous. But for the sake of exposition, in Tables 2 and 3, we only list numerical equilibrium solutions with $\sigma$ varying in steps of 0.2 .

The first two rows of Table 2 show that, as expected, the equilibrium prices of bus and rail transit decrease when rail operator places more weight on consumer surplus. Thus, for different values of $\sigma$, the pair of equilibrium fares are highest in standard private duopoly with $1.219 \mathrm{CNY}$ for bus and $2.643 \mathrm{CNY}$ for rail transit, and lowest in the mixed duopoly situation $(\sigma=1)$ with only $1.021 \mathrm{CNY}$ for bus and $0.002 \mathrm{CNY}$ for rail transit. Moreover, the synchronous decrease in bus and rail transit fares indicates the prices are strategic complements, which means the prices set by bus company decrease in response to the price reduction of Rail Company. Although both equilibrium fares move in the same direction (downward), the rate of decrease of rail transit fare is much greater. When the nationalization degree exceeds 0.8 , rail transit has a competitive advantage over bus in terms of its relatively low fare.

From Fig. 1a, it can be observed that the total demand of local public transport $\left(\mathrm{Q}^{*}\right)$ and rail transit $\left(\mathrm{Q}_{r}\right)$ increase gradually with the increase in $\sigma$. On the contrary, since rail transit attracts increasing numbers of travellers from buses due to its relatively low generalized cost, the market share of the bus quickly shrinks from 21.98 to $2.39 \%$. The logic behind the result can be explained as follows. The overall impact of nationalization on patronage is the combination of two effects: the first is increasing total demand for public transport, and the second is the shifting of market share between modes. Regarding rail transit, the more weight the rail transit firm places on consumer surplus, the greater the aggregate demand and rail operator's market share will be. Conversely, since the decreasing market share dominates the increase of total public transport demand, the equilibrium patronage of bus falls with the increasing degree of nationalization. Consequently, a further decrease in both firms' prices triggered by nationalization boosts the total public 


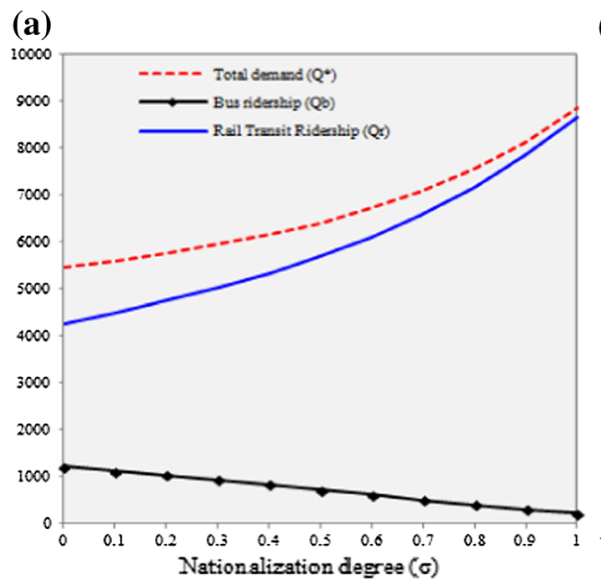

(b)

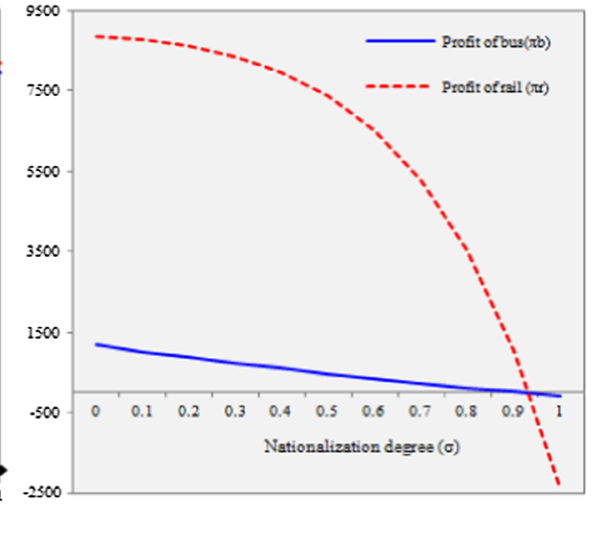

Fig. 1 The impacts of partial nationalization on equlibria in short run. a The effect of $\sigma$ on passenger demand, $\mathbf{b}$ the effect of $\sigma$ on operator's profits

transport demand. In such a case, the rail transit significantly erodes the market share of bus and the bus operator gradually loses its competitive advantage.

As illustrated in Fig. 1b, although the ridership of rail transit rises, the sharp reduction in fares cause the rail transit operator's profits to rapidly tail off. Due to the rail transit operator's relatively high operating cost, the low fare revenue cannot cover its variable operating costs when the degree of nationalization exceeds 0.9 . When $\sigma$ reaches 1 , it would be difficult for rail transit operator to remain profitable, the rail transit operator would require subsidies from local government. On the contrary, although the combined effect of fare reduction and shrinking ridership results in a considerable decrease in the profits of the bus, the relatively lower operating cost makes the bus operator profitable when the value of $\sigma$ does not exceed 0.9. In the extreme case of the rail transit operator fully considering consumer surplus $(\sigma=1)$, the bus operator cannot break even. As the profit is squeezed, the bus operator might drop out of business.

In the mixed duopoly, lower equilibrium prices and higher total transit demand have positive impacts on consumer surplus, implying consumer surplus rises by a considerable amount. Although the producer surplus falls with the increase in the degree of nationalization, these losses are relatively small compared with the gain in consumer surplus. Consequently, total social welfare increases slightly, this demonstrates the desirability of nationalizing rail transit operators.

The numerical results are consistent with the analytical results obtained in previous section and can be summarized in Remark 1:

Remark 1 An increase in the level of nationalization causes equilibrium prices to fall for both bus and rail transit. Moreover, there is a rise in social welfare when we move away from a standard private duopoly (SD) to a mixed duopoly (MD).

The above remark states that, in the process of nationalization, as the rail transit operator puts more weights on consumer surplus relative to its profit, the price 
competition in the mixed duopoly market become fiercer. Since travellers pay less in the move from a standard duopoly (SD) to a mixed duopoly (MD), consumer surplus, thereby boosting total public transport demand. Also, since the increase in consumer surplus can compensate for the loss of producer surplus, partial nationalization is socially preferable in terms of welfare improvement.

\subsection{The effect of nationalization ( $\sigma)$ on equilibria in the long run}

In the long run, since the operator has the ability to adjust its fleet size to match fierce market competitions, service frequency might be another strategic device. In this numerical case, we turn to Nash price-frequency competition and attempt to demonstrate how the operators respond to the progress of nationalization. The numerical equilibrium solutions for this Nash non-cooperative game are summarized in Table 3.

As Table 3 shows, the motive of increasing consumer surplus induces the rail transit operator to increase its frequencies and reduce fares. Since prices are strategic complements in this price-frequency game, the gradually decreasing rail transit fares provides an incentive to bus operator to defend its market share by responding with a fare reduction. On the contrary, in this case with endogenous frequency, it emerges that service frequencies are strategic substitutes. Thus, responding to the increase in rail transit frequency, the bus operator is forced to reduce its service frequency to prevent further deterioration of profitability (see Fig. 2a).

In comparison to Case 1, the most likely effect of adding service frequency as another strategic variable is that total public transport ridership has been greatly boosted, because the lower composite costs resulting from additional competitions over frequency increase the attractiveness of public transport. Similarly, when rail operator attaches a high weight to consumer surplus and a correspondingly low
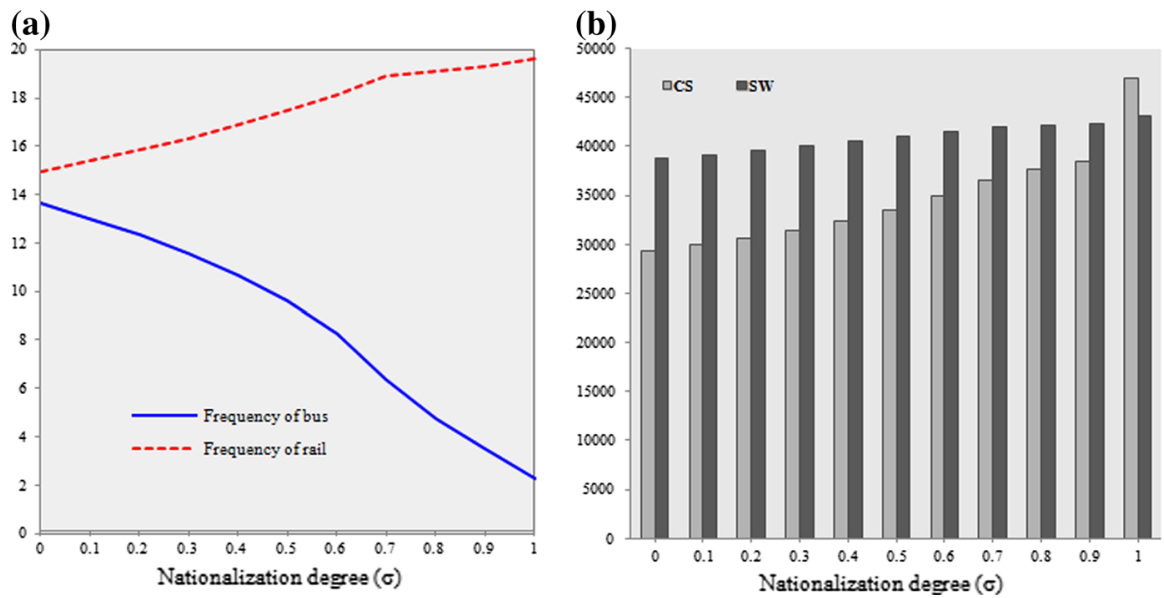

Fig. 2 The impacts of partial nationalization on equlibria in long run. a The effect of $\sigma$ on service, $\mathbf{b}$ the effect of $\sigma$ on consumer surplus and welfare 
weight on profit, its market share will be strengthened. On the other hand, conventional bus services become progressively worse off since its service levels are not as attractive as before. The ridership of buses diminishes fast. Then, in the case of full nationalization, a corner solution can be obtained in which the rail operator satisfies all demand. As far as operators' profits are concerned, both operators experience financial losses in the process of nationalization. Once the value of $\sigma$ exceeds 0.5 , the bus loses the commercial feasibility of operating services due to the negative profits. However, the welfare comparisons show that the increase in consumer surplus offsets the losses in operators' profits, which supports the desirability of a mixed oligopoly (see Fig. 2b).

The main finding of Case 2 is summarized in Remark 2.

Remark 2 In Nash non-cooperative game, with the motive of increasing consumer surplus (1) the rail transit operator intends to reduce fare and increases its service frequency. The bus operator strategically chooses to reduce both fare and frequency (2) the increase in consumer surplus offsets the losses in producer surplus, leading to the increase of social welfare.

The studies of mixed duopoly in industrial organization suggests that without other regulations, nationalization will heighten social welfare if there are relatively few private firms in the market and will degrade social welfare if there are relatively many private firms, assuming Cournot quantity-setting competition with an inelastic and linear demand function (Anderson et al. 1997; De Fraja and Delbono 1990). From the above numerical case studies, it can be concluded that full nationalization yields the highest level of social welfare in the public transport market. Thus, the numerical cases provide support for previous findings on Nash non-cooperative game in the context of an elastic and non-linear demand function.

The above numerical results rely heavily on specific dataset from Suzhou city. Hence, the generality of results is restricted to some extent. To determine whether the results are universal of specific, we carry out the following sensitivity analysis.

\subsection{Sensitivity analysis}

The numerical results of equilibrium configurations are dependent on a variety of system parameters. Among these parameters, the characteristics of transport demand and supply especially differ from one city to another. To this end, we focus on two parameters, namely, the users' cost perception (the demand parameter, $\xi$ ) and the producers' operating cost (operating cost coefficients of rail $c_{r l}$ ), which are important variations among cities. In what follows, we investigate the sensitivity of equilibria, in particular, the operators' fares and frequencies under changes in these two parameters.

\subsubsection{Sensitivity analysis with respect to users' cost perception ( $\xi)$}

Characterizing with different income level and different information technology, passengers in different cities may have different perceptions on travel cost variations. For example, when passengers in one city can achieve greater or more accurate travel information, they will have higher value of $\xi$. To investigate the 
(a)

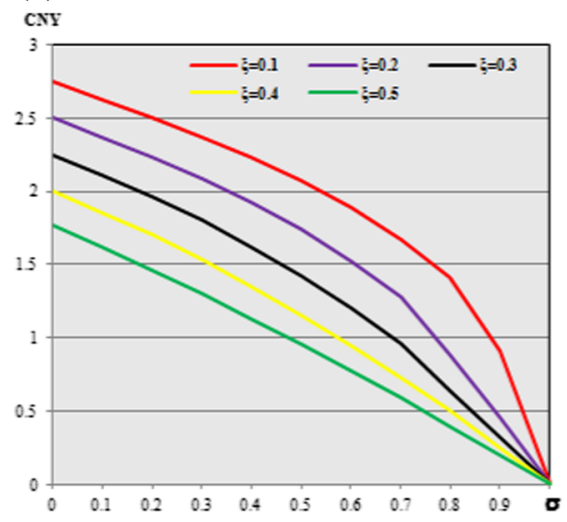

(c)

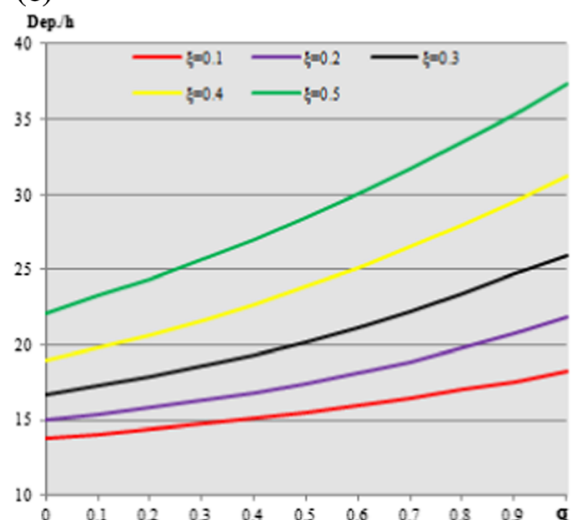

(b)

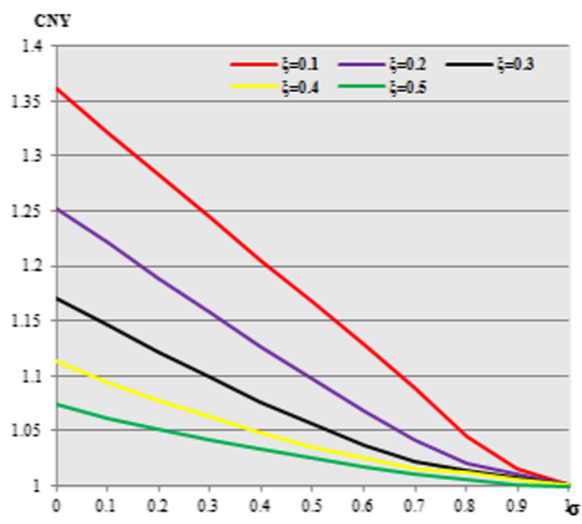

(d)

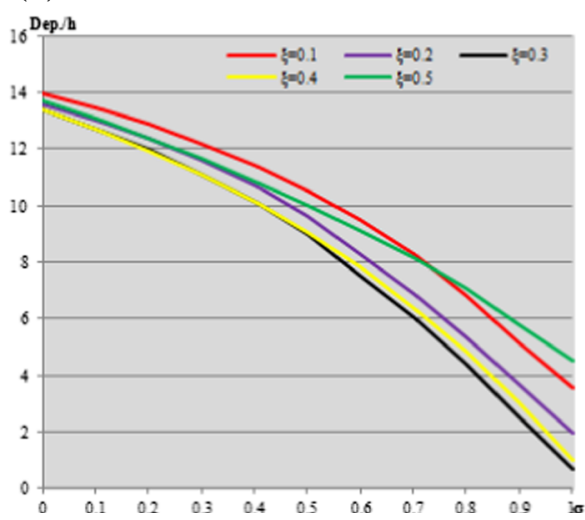

Fig. 3 Sensitivity of equilibrium fares and frequencies w.r.p to changes in $\xi$. a The rail transit fare change w.r.p $\xi$, b the bus fare change w.r.p $\xi$, $\mathbf{c}$ the rail transit frequency change w.r.p $\xi$, $\mathbf{d}$ the bus frequency change w.r.p $\xi$

likely response of equilibrium prices and frequencies to the change of demand parameter $(\xi)$, the value of $\xi$ varies from 0.1 to 0.5 with steps of 0.1 . In Fig. 3, we display the variations in the equilibrium fare and frequency under changes of demand parameter $(\xi)$.

Regarding the sensitivity of equilibrium results to parameter $\xi$, the following can be observed from Fig. 3. First, when residents of one city may have a higher accuracy in perceiving the travel costs (a higher value of $\xi$ ), the equilibrium fares for both bus and rail transit go down. Furthermore, the fare difference between bus and rail transit becomes smaller with the increase of value $\xi$, suggesting intense price competition. Second, when the travelers have higher cost sensitivities- $\xi$, the rail transit operator intends to provide more frequent services; the bus operator's operating behaviors in respond to changes of $\xi$ becomes complicated. Finally, making travelling demand more cost sensitive does not affect the qualitative results obtained in Remark 1 and Remark 2. 


\subsubsection{Sensitivity analysis with respect to suppliers' operating cost $\left(c_{i 1}\right)$}

In terms of operating costs, we observe that the cost efficiency of one transit operator has been affected by many factors, such as operational scales, organization structure, potential demand rate, regulatory regime and so on. Thus, the various operating environments in different cities do have great impacts on the operating efficiencies of operators. Since the slopes of frequency reaction functions are directly affected by the variable operating cost, they are likely to be important in determining the equilibrium results. To show how the operating cost difference affect the Nash equilibrium frequencies and prices, we keep the operating cost of bus fixed but the costs of operating rail transit services are changed for this $9 \mathrm{~km}$ transport link. With the increase of rail transit operating costs (from $40 \mathrm{CNY}$ to 198 CNY), the cost advantage of bus becomes strong (Fig. 4).

The main insight from this exercise is that: an increase in the operating cost of rail transit reduces the Nash equilibrium fare and service frequency for rail transit services. However, since the cost difference between bus and rail transit becomes

(a)

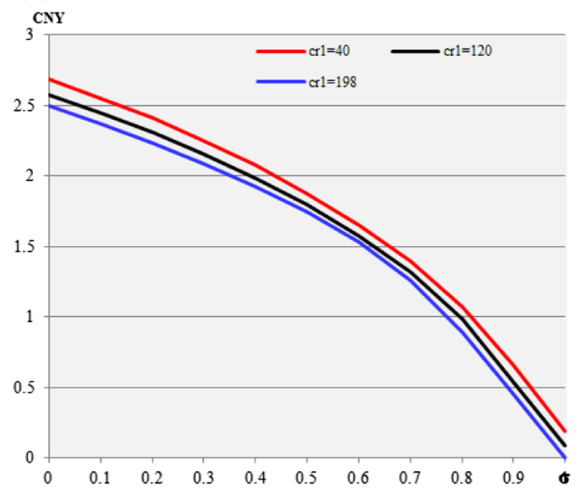

(c)

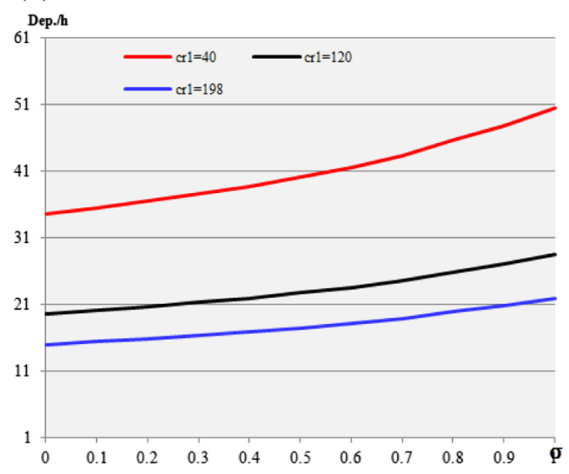

(b)

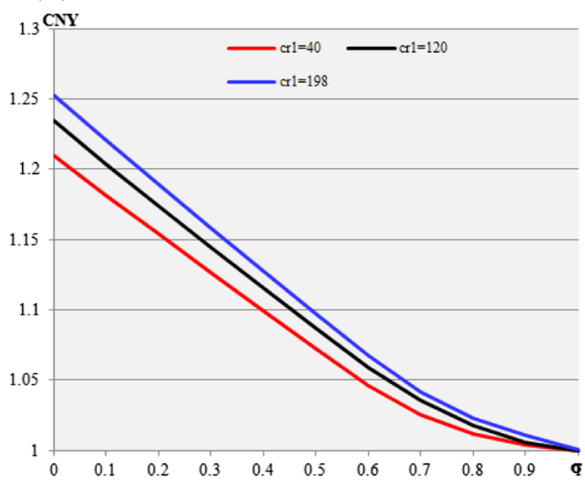

(d)

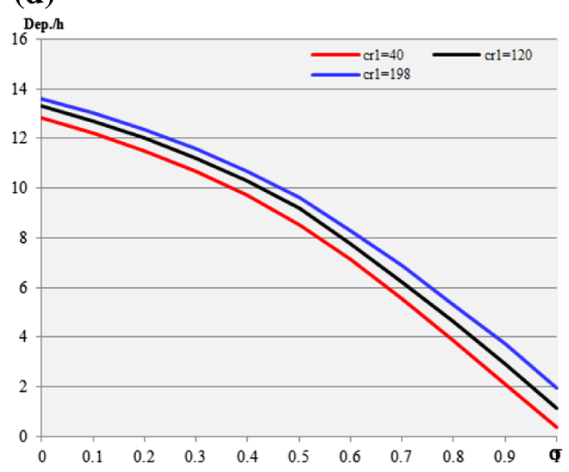

Fig. 4 Sensitivity of equilibrium fare and frequency with respect to changes in $\left(c_{r 1}\right)$. a The rail transit fare change w.r.p $c_{r 1}$, b the bus fare change w.r.p $c_{r 1}$, $\mathbf{c}$ the rail transit frequency change w.r.p $c_{r 1}, \mathbf{d}$ the bus frequency change w.r.p $c_{r 1}$ 
larger, the bus operator has a stronger cost advantage over rail transit. Thus, the bus operator can afford to run more frequent services and charge higher fare than before.

Not surprisingly, we found that the magnitudes of equilibrium outcomes are somewhat sensitive to the demand parameter and operating cost coefficient. However, the qualitative conclusions about the effect of nationalization degree on equilibrium results in Remark 1 and Remark 2 are found to be unaffected.

\section{Conclusions}

In this paper, the duopolistic interactions between one public rail transit operator and one private bus operator are presented as a Nash non-cooperative game. To investigate the effects of nationalization on equilibrium fares, service frequencies and associated welfare elements, two numerical cases based on Suzhou traffic data are analyzed and the main insights are presented as follows. Firstly, given the less flexible service frequency in the short run, the presence of one publicly-owned rail transit operator is a useful measure for approaching social optima. The more weight the rail operator attached to consumer surplus, the lower the equilibrium fare, leading to higher consumer surplus and social welfare. Secondly, in Nash noncooperative game with price and frequency competition, prices are a strategic complement. Due to this, when the rail operator reduces (or increases) its fare level, it forces the bus operator to do the same. Meanwhile, a marginal frequency increase (decrease) in rail transit service causes bus operator to decrease (increase) its frequency, indicating service frequencies are strategic substitutes. Finally, if no additional regulations are implemented, nationalizing one rail transit company is socially desirable both in Bertrand pricing game in the short-run and in Nash noncooperative game in the long-run. This result is in line with the previous studies' results on mixed oligopolies. That is, when the number of private companies is relatively small, privatizing one public firm degrades social welfare.

The analysis performed in the paper captures the present status of urban public transport market in many Chinese cities where newly introduced state-owned rail transit services compete with extant private bus companies. Although the above model is simply based on a duopolistic setup, the results have generated many managerial implications for the transport authority, public and private transit operators. Regarding the transport authority, it can use the nationalization as a mean to regulate the competitive urban transport market. Moreover, in both short and long term, the authority should carefully consider the amount of emphasis a public rail operator should place on consumer surplus compared to its own profit. The Suzhou case indicates that too much weight on consumer surplus may cause the private bus operator to reduce its service frequencies and consequently lose incentive to remain the market. On the other hand, too little emphasis on consumer surplus leads to higher fares, though it may yield higher frequent bus services. Thus a proper policy may be to find a happy compromise which will not only encourage private bus firms, render public rail self-supporting, but also yield adequate consumer surplus in the total social welfare. This paper has raised these important issues to understand such a compromise decision. As far as Chinese urban transport policy is concerned, 
none of these issues has been seriously considered in the context of the privatization/nationalization debate so far.

In future research, two avenues for extension could be considered. One is to extend the analytical model to include multiple private bus firms and determine whether the conclusions drawn from this paper remain valid. This extension requires finding the Nash equilibrium for a mathematically more complex traffic network model, perhaps utilizing a stochastic network. Another useful extension would be to examine the cooperative possibility between bus transit and rail transit.

Acknowledgments We would like to thank two anonymous referees for their insightful and helpful comments which substantially improve the quality of the paper. This work has been substantially supported by the National Natural Science foundation of China through projects (Nos. 71125004 and 71301112). China Postdoctoral Foundation (Grant No. 2015M571604) are also gratefully acknowledged for providing financial support for this research.

\section{Appendix 1: Equilibrium price in the short run}

Taking the partial derivatives of Eq. (15) with respect to fares yields:

$$
\frac{\partial O F_{i}}{\partial P_{i}}=\frac{\sigma}{\xi} \frac{\partial Q^{*}}{\partial P_{i}} \delta+Q_{i}+\left(P_{i}-c_{i 0}\right) \frac{\partial Q_{i}}{\partial P_{i}}
$$

where $\delta$ is an indicator variable, which takes on the value of 1 for rail transit and 0 for bus.

Then, plugging Eqs. (6) and (7) into (27), we can obtain the equilibrium fares by setting the corresponding results equal to zero:

$$
\frac{\partial O F_{i}}{\partial P_{i}}=Q_{i}\left[(1-\sigma) \delta-\left(P_{i}-c_{i 0}\right)\left(\xi M_{i}+\theta M_{j}\right)\right]=0
$$

After some manipulation, the above expression reduces to

$$
P_{i}^{N E}=\frac{(1-\sigma) \delta}{\theta M_{j}+\xi M_{i}}+c_{i 0}
$$

Next, we examine the effect of nationalization degree $(\sigma)$ on equilibrium fares. Partially differentiating the first order condition in Eq. (27) for rail transit with respect to its price yields:

$$
\begin{aligned}
\frac{\partial O F_{r}}{\partial P_{r}}= & \frac{\partial Q_{r}}{\partial P_{r}}\left\{(1-\sigma)-\left(P_{r}-c_{r}\right)\left[\theta-(\theta-\xi) M_{r}\right]\right\} \\
& +Q_{r}\left\{\left[(\theta-\xi) M_{r}-\theta\right]+\left(P_{r}-c_{r 0}\right)(\theta-\xi) \frac{\partial M_{r}}{\partial P_{r}}\right\}
\end{aligned}
$$

Substituting (7) and $\partial M_{r} / \partial P_{r}=\theta M_{r}\left(M_{r}-1\right)$ into (24), we can rewrite (30) as:

$$
\begin{aligned}
\frac{\partial^{2} O F_{r}}{\partial P_{r}^{2}}= & Q_{r}\left\{(2-\sigma)\left[(\theta-\xi) M_{r}-\theta\right]-\left(P_{r}-c_{r}\right)\left[\theta-(\theta-\xi) M_{r}\right]^{2}\right. \\
& \left.+\left(P_{r}-c_{r 0}\right)\left(\theta^{2}-\theta \xi\right) M_{r}\left(M_{r}-1\right)\right\}
\end{aligned}
$$


Because the sign of $\left[(\theta-\xi) M_{r}-\theta\right]$ and $\left(M_{r}-1\right)$ is negative, and other items in (31) are positive, it is easy to prove $\partial^{2} O F_{r} / \partial P_{i}^{2}<0$.

Taking the first derivative of (27) with respect to nationalization degree, we obtain $\partial^{2} O F_{r} / \partial P_{r} \partial \sigma=-\sigma Q_{r}<0$, and then we get:

$$
\frac{d P_{r}^{N E}(\sigma)}{d \sigma}=-\frac{\partial^{2} O F_{r} / \partial P_{r} \partial \sigma}{\partial^{2} O F_{r} / \partial P_{r}^{2}}<0
$$

\section{Appendix 2: Equilibrium price and frequency in the long run}

Partially differentiating the payoff function of operator $i$ with respect to frequency leads to:

$$
\frac{\partial O F_{i}}{\partial f_{t}}=\frac{\sigma}{\xi} \frac{\partial Q^{*}}{\partial f_{i}} \delta+\left(P_{i}-c_{i 0}\right) \frac{\partial Q_{i}}{\partial f_{i}}-c_{i 1}
$$

Substituting Eqs. (7) and (29) into (33) yields the equilibrium frequency for public transport service $i$ :

$$
f_{i}^{2}=\bar{Q}^{*}\left[\sum_{i} \exp \left(-\theta \bar{C}_{i}\right)\right]^{-\frac{\xi}{\theta}} \frac{\alpha_{2} \rho}{2 c_{i 1}} \exp \left(-\theta C_{i}\right)\left[\sum_{i} \exp \left(-\theta C_{i}\right)\right]^{\frac{\xi}{\theta}-1}
$$

Recalling the demand function for public transport service $i$ in Eq. (6), we replace $\bar{Q}^{*}\left[\sum_{i} \exp \left(-\theta \bar{C}_{i}\right)\right]^{-(\xi / \theta)} \exp \left(-\theta C_{i}\right)\left[\sum_{i=b, r} \exp \left(-\theta C_{i}\right)\right]^{(\xi / \theta)-1}$ with $\mathrm{Q}_{i}$ and select the positive root:

$$
f_{i}^{N E}=\sqrt{\frac{\alpha_{2} \rho}{2 c_{i 1}} Q_{i}}
$$

\section{Appendix 3: The effect of nationalization degree on equilibrium demand and welfare}

Analogous to the above propositions, we can analytically explore the effects of nationalization degree on equilibrium demand for bus and rail transit:

$$
\begin{gathered}
\frac{\partial Q_{r}^{N E}}{\partial \sigma}=\frac{\partial Q_{r}^{N E}}{\partial f_{r}^{N E}} \frac{\partial f_{r}^{N E}}{\sigma} \\
\frac{\partial Q_{b}^{N E}}{\partial \sigma}=\frac{\partial Q_{b}^{N E}}{\partial f_{r}^{N E}} \frac{\partial f_{r}^{N E}}{\sigma}
\end{gathered}
$$


Recalling Eqs. (7), (8) and (21), we have $\partial Q_{r}^{N E} / \partial \sigma>0$ and $\partial Q_{b}^{N E} / \partial \sigma<0$. In terms of total demand for whole public transport, we take the first derivative of $\mathrm{Q}^{*}$ with respect to nationalization degree $(\sigma)$, which yields:

$$
\frac{\partial Q^{N E^{*}}}{\partial \sigma}=\frac{\partial\left(Q_{r}^{N E}+Q_{b}^{N E}\right)}{\partial \sigma}=\frac{\partial P_{r}^{N E}}{\partial \sigma}\left(\frac{\partial Q_{r}^{N E}}{\partial P_{r}^{N E}}+\frac{\partial Q_{b}^{N E}}{\partial P_{r}^{N E}}\right)
$$

Substituting Eqs. (7), (8) and (18) into (38) and rearranging items provides the following:

$$
\frac{\partial Q^{N E^{*}}}{\partial \sigma}=-\xi \frac{\partial P_{r}^{N E}}{\partial \sigma} Q_{r}^{N E}>0
$$

\section{Appendix 4: The effect of nationalization degree on consumer surplus and producer surplus}

Recalling the expression of consumer surplus in (13), since $\partial Q^{N E^{*}} / \partial \sigma>0$, we have $\partial C S^{N E} / \partial \sigma>0$.

The producer surplus can be decomposed into two parts: the part associated with patronage and the part related to frequency:

$$
P S=\sum_{i=b, r} \pi_{i}=\sum_{i=b, r}\left(P_{i}-c_{0 i}\right) Q_{i}-\sum_{i=b, r}\left(c_{1 i}\right) f_{i}
$$

Differentiating $\sum_{i=b, r}\left(P_{i}-c_{0 i}\right) Q_{i}$ with respect to $\sigma$ and rearranging the terms gives:

$$
\begin{aligned}
\frac{\partial \sum_{i=b, r}\left(P_{i}^{N E}-c_{i 0}\right) Q_{i}^{N E}}{\partial \sigma}= & \frac{\partial P_{r}^{N E}}{\partial \sigma} Q_{r}^{N E}+\frac{\partial Q_{r}^{N E}}{\partial P_{r}^{N E}} \frac{\partial P_{r}^{N E}}{\partial \sigma}\left(P_{r}^{N E}-c_{r 0}\right)+\frac{\partial P_{b}^{N E}}{\partial \sigma} Q_{b}^{N E} \\
& +\frac{\partial Q_{b}^{N E}}{\partial \sigma}\left(P_{b}^{N E}-c_{b 0}\right)
\end{aligned}
$$

Substituting (7) for $\partial Q_{r}^{N E} / \partial P_{r}^{N E}$ and Eq. (18) for $\left(P_{r}^{N E}-c_{r 0}\right)$ into (41) yields:

$$
\frac{\partial \sum_{i=b, r}\left(P_{r}^{N E}-c_{r 0}\right) Q_{r}^{N E}}{\partial \sigma}=\frac{\partial P_{r}^{N E}}{\partial \sigma} Q_{r}^{N E} \sigma+\frac{\partial P_{b}^{N E}}{\partial \sigma} Q_{b}^{N E}+\frac{\partial Q_{b}^{N E}}{\partial \sigma}\left(P_{b}^{N E}-c_{b 0}\right)<0
$$

Given $\partial P_{r}^{N E} / \partial \sigma<0, \partial P_{b}^{N E} / \partial \sigma<0$ and $\partial Q_{b}^{N E} / \partial \sigma<0$, it can be easily shown that $\partial \sum_{i=b, r}\left(P_{r}^{N E}-c_{r 0}\right) Q_{r}^{N E} / \partial \sigma<0$.

Given the straightforward relationship $M_{r}^{N E}+M_{b}^{N E}=1$ and recalling the expressions for equilibrium frequencies in Eq. (20) yields:

$$
\sum_{i=b, r}\left(c_{1 i}\right) f_{i}=\sqrt{\frac{\alpha_{2} \rho c_{r 1}}{2} Q^{N E^{*}} M_{r}^{N E}}+\sqrt{\frac{\alpha_{2} \rho c_{b 1}}{2} Q^{N E^{*}}\left(1-M_{r}^{N E}\right)}
$$


Differentiating Eq. (43) with respect to $\sigma$ and rearranging the terms yields:

$$
\begin{aligned}
\frac{\partial \sum_{i=b . r} c_{i 1} f_{i}^{N E}}{\partial \sigma}= & \frac{\partial Q^{N E^{*}}}{\partial \sigma} \sqrt{\frac{\alpha_{2} \rho}{8 Q^{N E^{*}}}}\left(\sqrt{c_{r 1} M_{r}^{N E}}+\sqrt{c_{b 1}\left(1-M_{r}^{N E}\right)}\right) \\
& +\frac{\partial M_{r}^{N E}}{\partial \sigma} \sqrt{\frac{\alpha_{2} \rho}{2 Q^{N E^{*}}}}\left(\frac{\sqrt{c_{r 1}}}{2 \sqrt{M_{r}^{N E}}}-\frac{\sqrt{c_{b 1}}}{2 \sqrt{\left(1-M_{r}^{N E}\right)}}\right)
\end{aligned}
$$

After observing $\partial Q^{N E^{*}} / \partial \sigma>0$ and $\partial M_{r}^{N E} / \partial \sigma>0$, if the gap in operating costs between rail transit and bus is large enough $\left(\sqrt{c_{r 1} / M_{r}^{N E}}-\sqrt{c_{b 1} / M_{b}^{N E}}>0\right)$, then the sign of (44) is positive.

When the difference in production cost between rail transit and bus is large enough, it is certain that producer surplus decreases with an increase in the degree of nationalization $\left(\partial \sum \pi_{i} / \partial \sigma<0\right)$.

\section{References}

Anderson S, de Plama A, Thisse JF (1997) Nationalization and efficiency in a differentiated industry. Eur Econ Rev 41:1635-1654

Braid RM (1986) Duopoly pricing of congested facility. Working Paper No. 322, Columbia Department of Economics

Cantos-Sánchez P, Moner-Colonques M (2006) Mixed oligopoly, product differentiation and competition for public transport services. Manch Sch 74(3):294-313

Clark DJ, Jørgensen F, Pedersen PA (2009) Strategic interactions between transport operators with several goals. J Transp Econ Policy 32(3):385-403

Cremer H, Marchand M, Thisse J-F (1991) Mixed oligopoly with differentiated products. Int J Ind Organ $9(1): 43-53$

Czerny A, Höffler F, Mun S-I (2014) Hub port competition and welfare effects of strategic privatization. Econ Transp 3:211-220

D'Alfonso T, Jiang C, Bracaglia V (2014) Would competition between air transport and high-speed rail benefit environment and social welfare? Transp Res Part B 74:118-137

De Fraja G, Delbono F (1990) Game theoretic models of mixed oligopoly. J Econ Surv 4(1):1-17

De Palma A, Leruth L (1989) Congestion and game in capacity: a duopoly analysis in the presence of network externalities. Annales d'economie et de Statistique 15(15-16):389-407

Evans A (1992) Road congestion pricing: when is it good policy? J Transp Econ Policy 26(3):213-242

Fearnley N, Bekken J, Norheim B (2004) Optimal performance-based subsidies in Norwegian intercity rail transport. Int J Transp Manag 2:29-38

Fujiwara K (2007) Partial privatization in a differentiated mixed oligopoly. J Econ 92(1):51-65

Hong S, Zuo RY (2006) The calculation of public transit elasticities and policies suggestions. Urban Public Util 20(5):3-7

Huang J, Leng M, Parlar M (2013) Demand functions in decision modelling: a comprehensive survey and research directions. Decis Sci 44(3):557-609

Johansen KW, Larsen OI, Norheim B (2001) Towards achievement of both allocative efficiency and X-efficiency in public transport. J Transp Econ Policy 35(3):491-511

Jørgensen F, Santos G (2014) Charges on transport- to what extend are the passed on to users. Transp Res Part A 69:183-195

Kreps D, Scheinkman JA (1983) Quantity precommitment and Bertrand competition yield cournot outcomes. Bell J Econ 14(2):326-337

Lam WHK, Zhou J (1999) Stochastic transit assignment with elastic demand. J East Asia Soc Transp Stud 3(2):75-87 
Lam WHK, Zhou J, Sheng Z (2002) A capacity restraint transit assignment with elastic line frequency. Transp Res Part B 36(10):919-938

Mantin B (2012) Airport complementarity: private vs. government ownership and welfare gravitation. Transp Res Part B 46(3):381-388

Matsumura T (1998) Partial nationalization in mixed duopoly. J Public Econ 70:473-483

Matsumura T, Matsushima N (2012) Airport privatization and International Competition. Jpn Econ Rev 63(4):431-450

Matsushima N, Takauchi K (2014) Port privatization in an international oligopoly. Transp Res Part B 67:382-397

Nanjing Institute of City \& Transport Planning Co. Ltd. (2008) Annual Report of Suzhou Urban Transportation. Reported to the People's Government of Suzhou Municipality

Oldfield RH, Emmerson P (1986) Competition between bus services: the results of a modeling exercise. TRRL Research Report, Publisher: Transport and Road Research Laboratory

Quinet E, Vickerman R (2004) Principles of transport economics. Edward Elgar, Cheltenham

Suzhou Bus Co. (2008) Suzhou Bus Group Annual Report', Reported to the People's Government of Suzhou Municipality

Viton PA (1981) On competition and product differentiation in urban transportation: the San Francisco bay area. Bell J Econ 12(2):362-379

Wang JYT, Yang H (2005) A game-theoretical analysis of competition in a deregulated bus market. Transp Res Part B 41:329-355

Wichiensin M, Bell MGH, Yang H (2007) Impact of congestion charging on the transit market: an intermodal equilibrium model. Transp Res Part A 41:703-713

Williams HCWL, Abdulaal J (1993) Public transport services under market arrangements, part I: a model of competition between independent operators. Transp Res Part B 27(5):369-387

Yang H, Zhang A (2012) Effects of high-speed rail and air transport competition on prices, profits and welfare. Transp Res Part B 13:22-1333 